\title{
Imagem, imitação, presentificação: ambiguidade e agência das imagens produzidas pelas tecnologias dos brancos
}

Image, imitation, presentification: ambiguity and agency in the images produced by the technologies of non-indigenous people

\author{
Alice Villela* \\ *Universidade de São Paulo - São Paulo, SP, Brasil \\ Em pós-doutoramento \\ licevillela@gmail.com \\ https://orcid.org/0000-0002-4729-9412
}




\title{
Resumo
}

Este trabalho parte da proposta de entendimento do modo como imagens produzidas pelas tecnologias dos brancos, como as fotográficas e audiovisuais, são capturadas e compreendidas pelo pensamento dos Asuriní do Xingu, grupo indígena que vive no médio curso do rio Xingu, Pará, Brasil. A partir do reconhecimento de que a própria ideia de imagem pode ser problemática, procurei questionar seu uso na pesquisa e suas possibilidades tradutivas. Em vias de conhecer o que seja o domínio da imagem entre os Asuriní, investigo alguns conceitos nativos, especialmente a ideia de ayngava, que se refere à imitação, presentificação, termo empregado em alusão à fotografia e ao filme. Imitar, aqui, está longe de ser uma mera reprodução do que está ausente e aponta para um estatuto da imagem vivo em que o referente se presentifica ou é evocado. Por fim, trago a ideia de ambiguidade para pensar a relação dos indígenas com fotografias e imagens em movimento e também deles com seus outros, o que inclui os brancos.

Palavras-chave: imagem; imitação; ambiguidade; Asuriní do Xingu.

\begin{abstract}
The purpose of this work is to understand how the images produced by the technologies of non-indigenous people, such as photographic and audiovisual, are perceived and understood by the thought process of the Xingu Asuriní, an indigenous group living in the middle course of the Xingu River, in the Brazilian state of Pará. Starting from the recognition that the very idea of image can be problematic, I attempted to examine its use in research and the ways it can be translated. As a way of understanding the domain of the image among the Asuriní, I investigate certain native concepts, particularly the idea of ayngava, which refers to imitation, presentification, a term used in reference to photography and film. Imitating, in this context, is far from being a mere reproduction of that which is absent, and points to the status of the live image in which the referent becomes presentified or evoked. Finally, I introduce the idea of ambiguity in order to think about the relationship of indigenous people to photography and moving images, and also of themselves in relation to others, including to non-indigenous people.
\end{abstract}

Keywords: image; imitation; ambiguity; Xingu Asuriní. 
Este $\operatorname{artigo}^{1}$ trata da relação dos Asuriní do Xingu, povo tupi que vive na margem direita do rio Xingu no Pará, ${ }^{2}$ com imagens produzidas pelas tecnologias dos brancos, especialmente as fotográficas e audiovisuais. ${ }^{3}$ Do contato oficial, em 1971, até os dias atuais, as imagens produzidas pelas tecnologias dos brancos são marcadas, da perspectiva asuriní, pela ambiguidade e iminência de produzir efeitos, muitas vezes nefastos. Questionados a respeito da presença da fotografia no episódio do contato, a resposta corrente dos Asuriní associou a captura de fotos às mortes e aos adoecimentos que ocorreram nos anos subsequentes. Os Asuriní não tinham memória das imagens em si, mas dos efeitos que a tomada de fotografias teria gerado no primeiro encontro com os padres católicos. O esforço em compreender o que eles estavam me apontando, ao dizerem que a fotografia tirou o ynga (princípio vital) das pessoas fotografadas, levou-me a explorar as relações que podiam ser estabelecidas entre ynga e ayngava (imitação, imagem), e à construção da ideia de fotografia como objeto patogênico dotado de agência (ver Villela, 2015, 2016, 2018).

Neste trabalho emprego o termo "agência" em referência à noção assim desenvolvida por Alfred Gell (1998). É importante salientar que a proposta de pensar a presença de imagens produzidas pelas tecnologias dos brancos como imagens e objetos com agência veio ao encontro do que estava sendo expresso pelos indígenas, o que foi exemplar a partir do episódio da fotografia no contato oficial. Os efeitos deletérios das imagens fotográficas tiradas na ocasião do primeiro encontro dos Asuriní com os não indígenas colocam em relevo o que a

1 Este texto resulta da minha pesquisa de doutoramento intitulada O negativo e o positivo. A fotografia entre os Asuriní do Xingu, iniciada em março de 2011 e finalizada em dezembro de 2015 no âmbito do Programa de Pós-Graduação em Antropologia Social da Universidade de São Paulo, São Paulo, Brasil (ver Villela, 2016). Agradeço à Fundação de Amparo à Pesquisa do Estado de São Paulo Fapesp pela bolsa de pesquisa concedida (Proc. Fapesp: 2010/19789-5), à Profa. Dra. Sylvia Caiuby Novaes que orientou este trabalho com generosidade e dedicação, e à Profa. Dra. Regina Müller, que me levou aos Asuriní pela primeira vez e permaneceu como importante interlocutora em diferentes etapas da pesquisa.

2 Os Asuriní somam cerca de 200 pessoas (dados de 2015, ver Villela, 2016, p. 27) e vivem na Terra Indígena Koatinemo; estão divididos atualmente em duas aldeias, Koatinemo e Ita'aka.

3 Trato aqui de "imagens produzidas pelas tecnologias dos brancos" por vezes pontuando que são fotográficas e audiovisuais mesmo sabendo que a expressão pode apresentar problemas, principalmente por colocar numa mesma categoria tipos de imagens bastante diferentes e por desconsiderar as diferentes formas do desenvolvimento técnico da imagem (fotografia analógica, digital, cinema, televisão e vídeo). Quando for possível e/ou necessário, especificarei o tipo de imagem fotográfica ou audiovisual a que me reporto. 
fotografia faz ou é capaz de fazer. É preciso reconhecer que a ênfase asuriní ao se referirem às imagens tecnológicas dos brancos recai, em grande medida, na ideia de ação e agência mais do que na noção de objeto propriamente. Seguindo as trilhas das traduções asuriní para essas imagens dos brancos, veremos que não estão falando de objetos, mas de algo que se situa entre as categorias de ação e coisa, ambas cabendo, por exemplo, na palavra fotografia (composta por grafia, ato de gravar, inscrever), que é tanto a prática de fotografar quanto o papel ou a tela com a imagem revelada (a fotografia impressa, no computador, etc.). ${ }^{4}$

O estatuto vivo da imagem não é exclusividade dos Asuriní; entre diversos povos ameríndios das terras baixas sul-americanas parecem operar concepções de imagem que a relacionam a um mundo outro, e que estendem a ela qualidades ou a essência do ser representado. ${ }^{5}$ Entre os Asuriní, existe uma relação intrínseca entre a noção de imagem (ayngava) e o princípio vital (ynga), fundamentada no xamanismo ${ }^{6}$ como ponto de vista privilegiado desse grupo e da figura do xamã como organizador e catalisador dessa visão. ${ }^{7}$ Tal concepção de imagem, relacionada ao princípio vital, não cria a oposição entre verdadeiro e falso, ou verdadeiro e ilusório. Como uma representação que partilha de forma metonímica a qualidade (ou "essência") do representado, a imagem da pessoa estabelece uma relação metonímica com a pessoa, pois é constitutiva do ser. Narrativas e prescrições presentes no cotidiano asuriní indicam que nem tudo pode ser imitado sem efeitos, pois, aqui, estamos longe de uma ideia de representação como "imitação da aparência"; antes, a imitação está associada à partilha de qualidades e à evocação de propriedades do original. Objetos que

4 Agradeço ao parecerista ad hoc deste artigo por essa importante observação.

5 Por exemplo, os casos wajãpi (Gallois, 1988), kaxinawá (Lagrou, 2007), wauja (Barcelos Neto, 2008), dentre outros.

6 Nos rituais xamanísticos asuriní os xamãs viajam aos mundos dos espíritos ou entram em contato com eles na aldeia para a obtenção do ynga, princípio vital, ou do moynga, espécie de ynga suplementar que os Asuriní traduzem como "remédio", para cura e fortalecimento dos pacientes (imunara). Para uma etnografia dos rituais xamanísticos asuriní, ver Müller (1993).

7 Refiro-me, aqui, à ideia de Carneiro da Cunha (1998, p. 12, 17) de que o xamanismo opera no sentido de "interpretar o inusitado, conferir ao inédito um lugar inteligível, uma inserção na ordem das coisas" e apenas o xamã "[...] por definição, pode ver de diferentes modos, colocar-se em perspectiva, assumir o olhar de outrem [...]. E é por isso que, por vocação, desses mundos disjuntos e alternativos, incomensuráveis de algum modo, ele é o geógrafo, o decifrador, o tradutor." Destaca-se que a definição apresentada pela autora se refere à teoria do perspectivismo ameríndio (Viveiros de Castro, 2002). 
imitam, como o tayngava, boneco antropomórfico utilizado nos procedimentos de cura, são dotados de agência poderosa e por isso perigosa, e sua manipulação, restrita aos xamãs em contextos rituais.

A concepção da fotografia e de imagens audiovisuais como "coisa viva" não sustenta apenas a construção da ideia de objeto com ação patogênica capaz de produzir efeitos nefastos como o que aconteceu no momento do contato oficial em 1971. Na década de 1990, Müller (2000) descreve que os Asuriní avaliam como positiva a utilização de fotografias e vídeos na transmissão dos conhecimentos, especialmente ligados a práticas rituais que não são realizados com tanta frequência. Nos anos 2010, a circulação de fotografias produzidas nas décadas de 1970 e 1980 pelo fotógrafo Renato Delarole na aldeia evocaram lembranças e memórias dos parentes já falecidos; fotografias foram vistas e revistas, fizeram presentificar os bava, antigos, e reavivar vínculos de pertencimento. ${ }^{8}$ No entanto, o risco no trato com essas imagens é sempre iminente. Imagens fotográficas ou audiovisuais de parentes recém-falecidos não devem ser vistas pelo perigo de atrair o anhynga, espécie de espectro do morto, para perto da aldeia. Embora atualmente os Asuriní convivam com uma proliferação de imagens produzidas por diferentes equipamentos, e que eles mesmos tenham atuado intensamente nessa produção de imagens via aparelhos celulares, o perigo a elas associado permanece por perto e, se o produtor das imagens não é indígena, os riscos são ainda maiores. ${ }^{9}$

Como entender a presença dessas imagens entre os Asuriní e os modos de relação dos indígenas com elas? Este artigo segue as trilhas dos termos asuriní para se referirem às imagens produzidas pelas tecnologias dos brancos, que apontam para noções ligadas à imitação, presentificação, evocação e agência, em vias de compreender o modo como fotografias, vídeos, filmes, imagens da televisão, dentre outras, são capturadas pelo pensamento asuriní. Inicialmente apresento conceitos nativos ligados ao campo da imagem elucidando

8 A etnografia da circulação do acervo de Renato Delarole está disponível no artigo "O retorno dos antigos: compartilhamento do acervo fotográfico de Renato Delarole com os Asuriní do Xingu”, publicado pela Revista Mundaú (ver Villela, 2017).

9 Embora o fenômeno da produção de imagens via celular pelos indígenas seja muito presente no cotidiano da aldeia, é também muito atual e era apenas incipiente no momento em que realizei pesquisa de campo (anos 2012, 2013 e 2015), motivo pelo qual, neste texto, trato apenas das imagens fotográficas e audiovisuais produzidas por não indígenas. 
problemas e questões envolvidos nesta empreitada muitas vezes difusa que é pesquisar a temática das imagens em contexto e diálogo transcultural. ${ }^{10}$ Veremos como a palavra ayngava, traduzida pelos Asuriní como "imitação", é empregada em diversos âmbitos da vida indígena, adquirindo, em muitos casos, o sentido de "tornar presente" e evocar o referente. Em seguida, passamos aos termos asuriní usados para se referirem às imagens produzidas pelas tecnologias dos brancos - quase todos associados à raiz ayng, aos contextos em que são empregados e aos efeitos que os usos dessas imagens geram. Ao final do texto, trago a ideia de ambiguidade como noção filosófica operante na relação que os Asuriní estabelecem com a fotografia e o audiovisual de maneira geral, mas também na relação que estabelecem com os seus outros (espíritos e brancos).

\section{A problemática da imagem: notas sobre possibilidades tradutivas em contexto ameríndio}

O que seria imagem do ponto de vista dos Asuriní do Xingu? Com essa questão iniciei uma investigação que visava compreender o modo como as imagens produzidas pelas tecnologias dos brancos - inicialmente fotográficas - são capturadas e entendidas pelo pensamento asuriní.

Logo no início da investigação me dei conta de que o termo imagem não se prestava a atuar como uma categoria de entendimento comum, mediando a compreensão entre indígenas e antropóloga. Empregar o termo imagem para fazer a passagem entre culturas e línguas diferentes se tornou complicado e obscuro, não era das mesmas imagens que Asuriní e eu estávamos falando. Eu deveria me concentrar em conhecer os conceitos nativos que são empregados para designar cópia, desenho, figura, reflexo na água, duplo, dentre outros, para posteriormente compreender o que seriam, da perspectiva indígena, fotografias, vídeos, filmes, etc.

10 Refiro-me ao diálogo transcultural e não intercultural ou multicultural porque não se trata de diluir as diferenças e de encontrar um denominador comum. A ideia é que o diálogo se funda justamente no contraste de visões de mundo. Para usos do termo "transcultural", ver MacDougall (1998) e Garcia dos Santos (2013). 
Na etnografia de Müller (1992, 1993, 2000), que aborda a arte gráfica e o xamanismo asuriní, apareceram três termos-chave: ayngava, traduzido pela autora como imagem, réplica, medida e figura, palavra sempre precedida de um possuidor, ikwasiat, utilizado em referência aos padrões gráficos, e ynga, que se refere ao princípio vital dentro do corpo, à sombra e também aos duplos (traduzido também pela autora por "alma"). Alguns desses termos são usados pelos Asuriní em menção às imagens produzidas pelas tecnologias dos brancos; por exemplo, empregam ayngava precedido de um possuidor para se referirem às fotografias e aos filmes.

O termo imagem como categoria operadora da pesquisa criou ainda mais meandros à investida quando passei a considerar o sentido de imagem da perspectiva da antropóloga. De que imagem estava falando? Qual conceito e que ideias relativas a imagem levei ao campo na expectativa de obter uma tradução asuriní?

É, de certa forma, senso comum que a imagem representa ou substitui algo ausente ao reproduzir certos aspectos da aparência visível da pessoa ou do objeto. Wolff (2005) propõe tomar a ideia de representação ao "é da letra" e afirma que a imagem representa no sentido bem simples de que torna presente qualquer coisa ausente, ela representa o que ela não é. O autor chama atenção para a relação entre a imagem e aquilo da qual é uma imagem; imagens nos remetem à coisa ausente e nos possibilita vê-la, pensá-la, ou evocá-la. Assim, "uma imagem não é então, uma coisa, é uma relação com uma outra coisa. Toda imagem é uma imagem de alguma coisa" (Wolff, 2005, p. 21, grifo do autor).

É Vernant (1990) quem nos ajuda a entender historicamente as diferentes noções de imagem no Ocidente. Na Grécia Antiga, teríamos os ídolos arcaicos, objetos utilizados em contextos religiosos que operavam a figuração de mortos e deuses. O ídolo seria um símbolo por intermédio do qual uma força do além, isto é, um ser fundamentalmente invisível, se presentificava no mundo. Tais figuras, como é o caso dos kolossói e do xoánon analisados pelo autor, pretendem estabelecer com a força sagrada "uma verdadeira comunicação", "um contato autêntico" ao torná-la presente. No entanto, na confluência dos séculos $\mathrm{V}$ e IV a.C. a teoria da mimesis, da imitação, esboçada por Xenofonte e sistematizada por Platão, marca, na cultura grega, o momento em que se concluiu a versão que conduz da "presentificação do invisível para a imitação da aparência" (Vernant, 1990, p. 318-319) em que: 
O símbolo através do qual uma força do além, isto é, um ser fundamentalmente invisível, é atualizada, presentificada neste mundo, transformou-se em uma imagem, produto de uma imitação versada que, pelo seu caráter de técnica erudita e de processo ilusionista, introduz-se desde então na categoria geral do "fictício" - que nós chamamos de arte. A partir daí, a imagem depende do ilusionismo figurativo, tanto mais que não se aparenta ao domínio das realidades religiosas.

Contudo, embora segundo Vernant a imagem tenha deixado de encarnar o invisível, o além e o divino, constituindo-se como imitação da aparência, essa separação não parece ter sido tão clara e efetiva, pois as imagens, especialmente as técnicas, talvez pela completa identidade com aquilo que representam, continuam a provocar confusão e ambivalência. ${ }^{11}$ Olhamos para a televisão e acreditamos ver a própria realidade, sem representação; o trabalho da produção da imagem não é mais visto na imagem, sendo a imagem o real (registrado); essa é a ilusão, segundo Wolff (2005, p. 44), que consiste em fazer crer que a realidade tem o poder de sua própria representação. Gonçalves (2010) afirma que a origem do que representa a imagem para a cultura ocidental não estaria no eikon (imagem propriamente dita), mas no eidolon (simulacro), pois a essência da imagem nos dias de hoje estaria relacionada àquilo que produz ambiguidade na percepção, o que coloca em relação concepções de originalidade e cópia, o que revela e o que engana. Debray (1992) vai dizer que vivemos um "arcaísmo pós-moderno" em que há convergências entre as imagens produzidas atualmente e os ídolos arcaicos; no entanto, embora a espiral das imagens nos faça repassar pelos mesmos pontos, não estamos no mesmo nível ontológico. Diz o autor que a imaterialidade do vídeo reativa aspectos do "colosso" arcaico: uma imagem sem autor e autorreferente se coloca, automaticamente, em posição de ídolo, e nós de idólatras, tentados a adorá-la diretamente (Debray, 1992, p. 411-421).

11 Uma referência fundamental para pensar a passagem às novas técnicas de reprodução de imagens é o clássico texto de Benjamin (1987) "A obra de arte na era de sua reprodutibilidade técnica", que apenas menciono dado o caráter sumário da discussão acerca da presença das imagens no Ocidente neste artigo. Se, para Benjamin, a reprodutibilidade técnica causou a deterioração da "aura" da obra de arte, o material asuriní analisado neste artigo nos permite restituir, de outra maneira, a "aura" e a vida às imagens técnicas. 
Imagem, entre nós, pode ser muitas coisas: um quadro, uma fotografia, um filme, mas também uma imagem mental, uma lembrança, um sonho. Essa constatação, de certa forma intuitiva, encontrou eco em alguns estudiosos do tema. Hans Belting (2004, p. 17, tradução minha), no início da obra Pour une anthropologie des images, afirma: "....] o discurso sobre as imagens se tornou um sujeito da moda [...] o termo 'imagem', que não cessa de emergir por todos os lugares, age como um narcótico que dissimula esta evidência de que não é sempre das mesmas imagens que nós falamos".

Mitchell (1986), em seu livro Iconology: image, text, ideology, apresenta formulações interessantes sobre o fenômeno chamado "imagem" (imagery). A primeira consideração trata da variedade de coisas que correspondem a esse termo.

Nós falamos de pinturas, estátuas, ilusões óticas, mapas, diagramas, sonhos, alucinações, espetáculos, projeções, poemas, padrões, memórias, e ainda ideias como imagens, e a absoluta diversidade dessa lista de coisas torna qualquer entendimento sistemático e unificado impossível. (Mitchell, 1986, p. 9, tradução minha)..$^{12}$

Se, mesmo entre nós, não falamos da mesma coisa quando o tema é imagem, o que se passa quando projetamos essa categoria no universo ameríndio?

A questão da tradutibilidade dos termos é mais complexa do que parece. Por mais que os Asuriní utilizassem as palavras: imagem, desenho, fotografia e vídeo o que eles faziam para traduzir seus próprios conceitos para o português -, não estavam se referindo às mesmas coisas que eu. Fotografias podem ter intencionalidade e agir, câmeras de vídeo captam o ynga das pessoas e mostram suas sombras ao reproduzir sua imagem. Tratava-se de referentes muito diferentes, aludidos por meio das mesmas palavras.

Referentes diferentes ou mundos diferentes remontam à discussão das ontologias, o que nos auxilia a compreender o estatuto da imagem ameríndia.

$12 \mathrm{O}$ argumento do autor se afasta da pretensão de definir imagem por sua natureza, e de uma maneira universal, para dar lugar à compreensão de quais são os tipos de imagens existentes. Assim, segundo Mitchell (1986, p. 10), as imagens podem ser: gráficas (como as pinturas, as estátuas e os desenhos); óticas (como os reflexos no espelho e as projeções); perceptivas (como as aparências); mentais (como os sonhos, as memórias e as ideias); e verbais (como as metáforas e as descrições). 
Viveiros de Castro (2004) aponta para o fato de que o perspectivismo ameríndio coloca o problema da tradução de mundos. Em sua formulação a respeito do que seja a "equivocação" (ou o método da equivocação controlada), o autor chama atenção não para falhas no entendimento - entre índios e antropólogos, por exemplo, como procurei mostrar ao falar dos mal-entendidos em torno da tradução do termo imagem -, mas para a compreensão de que os entendimentos envolvidos em uma situação como essa são necessariamente diferentes, pois dizem respeito a diferenças nos próprios mundos que estão sendo vistos. De acordo com esse método, talvez, a questão mais pertinente seria a de saber, afinal, o que é uma fotografia para os Asuriní? Ou, o que está sendo expresso ao empregarem o termo "filme"?

Na Amazônia, o problema da imagem é geralmente um problema de objeto porque, na ontologia animista ou perspectivista (cf. Descola, 2005 e Viveiros de Castro, 2002), lá onde encontramos a separação de intencionalidades ou "almas" e formas físicas ou vestimentas corporais, as maneiras de transformação ou corporificação de seres podem esconder imagens que chamamos "objetos". As imagens como objetos podem ter uma intencionalidade humana, da mesma maneira que os outros seres e imagens mentais (ou do sonho) podem ser o protótipo de objetos. Poderíamos dizer que é possível pensar objetos exteriores ao mundo asuriní (a fotografia, por exemplo) como envolvidos nas "redes personificadas de relação" - para utilizar um termo empregado por Cesarino (2012).13

Entre os Asuriní, há relação entre a imagem (ayngava) e o princípio vital compartilhado entre humanos e espíritos (ynga). Müller trabalha com a ideia de que, apesar de se tratar de uma diferença apenas morfofonêmica entre ynga e ayngava, pois designam coisas diferentes, o significado de uma constitui o significado da outra: ayngava (imagem) contém ynga (princípio vital). A conclusão de Müller (2000, p. 186) sobre essa relação (entre ayngava e ynga) “[...] é que, para os Asuriní, a ‘imagem', ela própria,éconstitutiva da pessoa (enquanto ser), distinguindo-se do princípio vital/substância, ynga, por sua reprodução

13 O autor propõe analisar a escrita e os desenhos aplicados aos corpos marubo como transformações de conhecimentos xamânicos. Cesarino fala de um processo no qual os "livros", enquanto objetos utilizados nas escolas indígenas, se integram nas relações personificadas, e explica: “O pensamento personificante pode se estender potencialmente a tudo, assim prevendo agentes (e, quiçá, agentes dentro de agentes) lá onde encontramos apenas objetos” (Cesarino, 2012, p. 123). 
plástica, mas igualmente princípio vital e não apenas reprodução, no sentido de representação de algo ausente". Relações entre ayngava e ynga estão na base da ideia de que imagens, incluindo aí as fotográficas e audiovisuais, podem ter agência (cf. Gell, 1998).

O ynga é um daqueles termos de difícil tradução, pois se refere a uma gama abrangente de fenômenos diferentes, dificilmente traduzíveis por um único termo, mas, no esforço por compreendê-lo, acabamos empregando traduções tais como "princípio vital", "alma", "sombra", "espírito". Essa complexidade não é, nem de longe, uma novidade. Diversos etnólogos como Viveiros de Castro (1986, p. 495) e Garcia (2010, p. 96) já apontaram para os desafios envolvidos nesse empreendimento ao problematizar o uso frequente de termos como tradutores de ideias a respeito da separação da pessoa ameríndia e de enunciações a respeito da morte em uma única ideia. ${ }^{14}$

Em seus estudos acerca da arte gráfica e do xamanismo asuriní, Müller $(1992,1993,1996)$ traduziu o ynga por princípio vital compartilhado entre seres viventes e manipulado pelos xamãs nos rituais xamanísticos. Ynga seriam, também, as manifestações desse princípio vital animado no corpo como a voz, a pulsação, as batidas do coração, além da sombra de alguém projetada no chão (Müller, 1993, p. 170). Nos rituais xamanísticos, os espíritos xamãs primordiais (Tivá, Apykwara e Karovara) ${ }^{15}$ são chamados para dançar e tomar mingau junto aos xamãs, transmitindo-lhes ynga que são aplicados aos pacientes que estavam ameaçados de perdê-los. No corpo do doente o ynga é introduzido e "guardado dentro" por intermédio de sopros, massagens, fumaça de tabaco e mingau ingerido.

14 Entre os Asuriní, quando uma pessoa morre suas partes constituintes se separam em três: ynga, ossos e anhynga. O ynga (princípio vital) vai para o céu; este princípio animado da pessoa vai para mairakwera, o caminho onde mora Maíra, herói criador que concebeu o mundo dando vida às coisas com baforadas de cigarro. Os ossos, (gakynguera, $g a=$ dele, $k y n g=$ ossos, era = sufixo que indica passado, o que foi) são enterrados na tavyve, casa grande que se localiza no centro da aldeia. O espectro anhynga é liberado, segundo relatos, depois de mais ou menos três dias, fica por um tempo perambulando nas matas ou roças abandonadas, as capoeiras (kafera), e depois se dissipa. Para mais informações a respeito dos componentes da pessoa Asuriní e suas relações com a morte, ver Villela (2016, cap. 2).

15 Segundo Müller (1993, p. 189-190), os espíritos xamãs primordiais são espécies sobrenaturais que parecem reproduzir a sociedade humana em outros mundos e que, no passado mítico, desempenhavam funções de xamãs, associados à cura de doenças. 
No entanto, o ynga não estaria apenas associado ao tratamento de doentes, mas também à caça e à agricultura, bem como à preservação da vida do guerreiro. Ao afirmar que os espíritos Tajaho (porco-do-mato) e Arapoá (veado), ligados à caça e à agricultura, respectivamente, também transmitem ynga, Müller (1993, p. 171) conclui que a noção de ynga trata do “[...] princípio vital existente, não só no corpo das pessoas e elemento constitutivo de seres viventes, humanos e espíritos, mas extensivo aos resultados das ações que estes seres executam sobre a natureza". No caso do guerreiro que recebe $y n g a$, ele não padece por conta da diminuição do princípio vital, como acontece com os doentes, mas, ao contrário, sofre pelo seu excesso: “[...] segundo os Asuriní, ele é tatuado para se tirar de seu corpo o sangue de sua vítima, que 'fica na barriga, dói e pode lhe fazer mal"' (Müller, 1993, p. 170). O guerreiro tatuado nos rituais do Turé16 passa pelo processo de sangramento, como se pudesse ser retirado de seu corpo uma substância, que Müller se pergunta se seria o ynga da vítima.

\section{Ayngava: imitação, presentificação e perigo}

Ao descrever como se dá a "incorporação de personagens míticos" no ritual Turé, através da figura do corpo todo pintado de preto (pintura ajemo'ona) e decorado com penugem de gavião, Müller (1993, p. 111) diz que "receber a penugem de gavião requer muita concentração. Pode-se ter tontura e até ficar doente, sinal deste contato, perigoso principalmente para os jovens". A pintura ajemo'ona e as penas de gavião são tecnologias de transformação do corpo no ritual. A figuração dos seres míticos permite investir os corpos dos avá (gente) de capacidades relacionadas aos espíritos, estabelecendo um contato, muitas vezes perigoso, entre a pessoa e estes seres dos quais se partilham as qualidades.

Contudo, não é apenas em contextos rituais que a aproximação aos espíritos pode apresentar riscos. Em alguns casos, justamente por não estar relacionada à atividade ritual, a partilha de qualidades adquiridas por imitação desses seres pode trazer ainda mais prejuízos. Ao me contar sobre o ensino de

16 O Turé é um complexo ritual que atualiza a cosmologia e as narrativas míticas, articulando diversas instituições sociais como a guerra, a iniciação dos jovens e a celebração dos mortos, além de ser o nome das flautas tocadas no ritual. Ver Müller (1993). 
elementos dos rituais Turé e Tauva ${ }^{17}$ na escola indígena, o jovem professor Koatireí me disse que nas atividades em sala os professores podem contar as histórias relacionadas ao personagem Tauva, falar sobre os objetos usados no ritual, mas não podem ensinar os cantos que as tauyva (cantadoras que entram em contato com os espíritos) executam sob o risco de provocar reações descontroladas do espírito Tauva, que seriam sentidas pelas cantadoras. Como me explicou o jovem indígena, reproduzir o canto é uma forma de imitar (ayng) o movimento das tauyva que, ao cantar, estabelecem contato com os espíritos Tauva. Dessa forma, se alguém reproduz seus cantos, pode evocar os espíritos de maneira desgovernada.

A imitação de alguns animais como a coruja (urukure'a), o inhambu (inamu) e o $u_{r u}{ }^{18} \mathrm{em}$ determinadas circunstâncias pode representar riscos. De noite na mata não se pode imitar a coruja (nayngavi urukure'a), pois ela se transforma em onça e vem atacar quem a chamou. A explicação para a interdição me foi fornecida pelo jovem xamã Parajuá, que diz "coruja já comeu gente" e recorre à história de Tivaruma ${ }^{19}$ para se fazer entender. No início da narrativa: "Tivaruma vai no mato com seus parentes. Os parentes dele estavam brincando, imitando coruja. A coruja veio na forma de todo tipo de onça e comeu os parentes de Tivaruma. Só ele sobreviveu pois estava virando pajé." A história segue e Tivaruma, sozinho (sem parentes), passa por inúmeras peripécias até encontrar o caminho de Tivá.

Ao repetir a história de Tivaruma com mais detalhes, Parajuá utiliza o verbo "chamar" (ejat) em vez de "imitar" (ayng) a coruja. Os parentes de Tivaruma teriam chamado a coruja ao imitá-la. O perigo de imitar certos animais ou espíritos consiste no fato de que, ao imitá-los, estamos evocando-os, o que nos torna extremamente suscetíveis a suas ações predatórias. O espírito Tauva

17 O ritual Tauva é liderado por mulheres que cantam (tauyva) consideradas espécie de xamãs, e são acompanhadas pelas dançarinas que respondem o coro. Os ritos da tatuagem dos guerreiros, jovens iniciados (kauiraô) e o choro dos mortos na festa do Kawara são partes do Tauva. Para mais informações, ver Müller (1993).

18 Não pude obter o nome deste animal na tradução em português. Sei que se trata de uma ave aparentada ao inhambu, mas um pouco menor.

19 Tivá é um espírito que no tempo mítico era xamã. O Tivá vem nos rituais para tomar mingau e fornecer ynga e moynga aos doentes. Xamãs que "têm Tivá" trazem esses espíritos para a aldeia e também convivem em seus mundos, casando-se e tendo filhos com eles. Tivaruma é o que vai se tornar Tivá. O sufixo ruma corresponde ao futuro nominal, “o futuro Tivá" (cf. Müller, 1993). 
não pode ser imitado (nayngavi Tauva) na beira do rio sob o risco de os peixes virarem todos Tauva. Caso alguém imite o inhambu ou o uru de noite eles vêm e viram anhynga, espectros dos mortos, aparecem em forma de pedaços de corpos de gente que já morreu. Não se pode imitar o espírito Karovara na beira d’água, sob o risco de ele cortar o corpo da pessoa por dentro, levando-a à morte.

Imitar na língua asuriní é ayng:20 jeaynga, eu imito; janejaynga, nós imitamos; e gauaynga, ele imita; tapy'yia ukanu uaynga, índio bravo imitou gavião. Na palavra ayngava, à raiz ayng é acrescido o sufixo av(a), que Müller (1993, p. 242) define como sufixo formador de nome de circunstância. Uma tradução um pouco diferente para o sufixo av é fornecida por Ruth Monserrat (1998), na publicação em que tece observações acerca da língua asuriní; ela define $a v$ como "nome de lugar ou instrumento", e o complemento (a) é um outro sufixo nominal. Monserrat (1998, p. 35) cita alguns exemplos: a oração ki je kiava (aqui é meu dormitório, lugar de dormir) ou a palavra kywava (pente, objeto para piolho), ou ainda, tevutiava (banheiro, lugar de cagar). Dessa forma, uma tradução mais conveniente para ayngava poderia ser "objeto (ou instrumento) que imita", ou "lugar da imitação", para a acepção relacionada a lugar, que Müller também enfatiza ao propor falar de av como sufixo formador de nome de circunstância. Embora Müller (1993, p. 245) tenha traduzido ayngava diretamente por "imagem, réplica e representação", creio ser importante recuperar a acepção da palavra "imitação", raiz do verbo ayng presente no termo ayngava.

No entanto, empregar apenas a palavra "imitação" para tradução do verbo ayng pode ser uma armadilha por remeter a uma cópia que difere do original em essência e, embora os Asuriní tenham optado por traduzir ayng pelo verbo imitar, a palavra não dá conta dos vários e complexos sentidos que estão sendo acionados pelo termo. Opto, portanto, pela tradução do termo ayngava como "imagem, figura, réplica, imitação, presentificação, objeto que imita, torna presente". Imitar, aqui, estaria mais próximo de noções de mimesis, de partilha de propriedades e de evocação das qualidades do protótipo - como desenvolvidas por Taussig (1993) ou por Vernant (1990), do que a mera imitação da aparência, o que comprovam as diversas interdições em se imitar espíritos ou animais descritas anteriormente.

20 Copiar seria referido como peapai jave (fazer igual). 
Todavia, é preciso que se diga que não é em todos os contextos que imitar implica investir o objeto de capacidades do original. No uso cotidiano o termo ayngava pode ser empregado para designar uma reprodução ou uma réplica de qualquer objeto. Dessa forma, o desenho de um homem (ava) é avarayngava, ou a representação estilizada de um pássaro (uirá) é chamada uirarayngava. Um outro exemplo sobre os usos correntes do termo ayngava é a maneira como os Asuriní se referem às cédulas de dinheiro. Para identificar as diferentes notas de 2, 5,10, 20, 50 e 100 reais eles se reportam às figuras representadas em cada unidade de papel. A nota de 100 reais, que traz o desenho do peixe tucunaré, é referida como tucunarerayngava; a de 5 reais, com a imagem da arara, é ararayngava; e assim por diante.

Tal constatação, exemplificada anteriormente, não enfraquece a ideia da imagem e imitação como partilha de capacidades e propriedades; pelo contrário, ela nos auxilia a circunscrever as ocasiões em que imitação e presentificação operam. Em situações rituais ou extrarrituais, em que são evocados seres e espíritos, tal noção parece se efetivar. De maneira semelhante, máscaras, efígies e miniaturas ameríndias que figuram o invisível não presentificam intencionalidades humanas a qualquer momento ou em qualquer situação; isso acontece, sobretudo, nos momentos rituais, o que não impede que esses objetos e imagens carreguem com eles a potencialidade de agir e de que, a qualquer momento, algo aconteça.

\section{Imagens tecnológicas dos brancos}

Ayngava com o sentido de "imagem, objeto ou instrumento que imita, torna presente" parece extremamente apropriado para pensar as imagens técnicas produzidas pelos brancos. Como me explicou o jovem Parajuá, ayngava pode ser utilizado para designar imagens fotográficas e fílmicas porque "elas imitam de verdade". Note-se, nesse comentário, a ênfase à ação de imitar, raiz do verbo ayng que compõe a palavra ayngava, a que os objetos se reportam. Portanto, trata-se menos de pensar ayngava como "nome de lugar, objeto ou instrumento" do que da indicação da ação ou dos efeitos que eles produzem ou aos quais estão associados. Agência e objeto, aqui, apresentam-se de forma inseparável. 
As primeiras menções ao modo como os Asuriní se referem aos equipamentos e tecnologias de produção de imagens e sons dos brancos aparecem no artigo de Müller, "Corpo e imagem em movimento: há uma alma neste corpo", publicado em 2000 pela Revista de Antropologia. A devolução de imagens em vídeo, registrando sobretudo rituais asuriní produzidas na década de 1990, bem como a exibição de filmes de ficção e de produções realizadas entre outros grupos indígenas, ${ }^{21}$ é o pretexto para a reflexão sobre o uso da imagem em movimento na pesquisa antropológica, transmissão de conhecimento através das práticas rituais no contexto intercultural e noções de representação e imagem na arte asuriní (Müller, 2000, p. 176).

Diante da câmera e da televisão, os Asuriní, diz Müller (2000, p. 175), “[...] reelaboram os conceitos ynga e ayngava, princípio vital e imagem, 'alma'/ sombra e desenho, bem como suas concepções sobre captação de imagem e morte/'perda da alma'". Além disso, os nomes dados pelos Asuriní à televisão, à imagem em movimento e à câmera de vídeo permitem algumas considerações sobre a experiência do contato dos indígenas com um instrumento tecnológico que, segundo Müller (2000, p. 184), logo incorporaram como meio de aprendizagem e transmissão de conhecimento.

A reelaboração de conceitos nativos diante das novas imagens tem por efeito alargar suas possibilidades tradutivas. Por exemplo, nos depoimentos de Marakauá e Apebu: "oreayngava onhynhyn" e "oreynga pupé", cuja tradução apresentada é: "nosso desenho está entrando [na televisão]" e "nossa sombra fica dentro" (Müller, 2000, p. 175), os Asuriní traduzem oreayngava por "nosso desenho" e oreynga por "sombra" em comparação à sombra de um corpo no chão, como indicou Manduka. Mas a revisão dos termos não é esforço apenas dos indígenas, Müller (2000, p. 175) também reelabora suas próprias definições do que seja ynga e ayngava e apresenta uma outra equação para dar conta da construção oreayngava onhynhyn e oreynga pupé, que é a seguinte: “[...] entre o corpo e a imagem em movimento na TV há uma alma, desenho e sombra". O termo "alma" aparece como alternativa de se traduzir o ynga por "sombra" - o que é evidenciado pela tradução de "televisão" no filme por "caixa da alma" - ao mesmo

21 Vídeos do projeto Vídeo nas Aldeias que, na época, integrava o Centro de Trabalho Indigenista (CTI), ao qual o projeto de Müller estava vinculado. 
tempo que agrega uma nova camada de sentido, pois a "alma" estaria na junção do "desenho" e da "sombra".

Em minhas pesquisas (ver Villela, 2016), a televisão foi aludida por meio do termo yngyrú, claramente em referência à "sombra" (imagem em movimento que a TV projeta) e à fala reproduzida, índice da presença do ynga. Parajuá foi categórico: "Televisão é yngyrú porque a gente aparece e sai voz, a minha avó chamava assim." o prefixo yrú, segundo me explicaram, refere-se à ação de "guardar", colocar dentro (pupé); jeryrú, termo que utilizam para se referir à roupa, foi traduzido como "o que a gente usa para guardar o corpo". Koatireí falou em "coisa que guarda a alma", empregando a tradução de ynga por "alma". Outro termo mais recentemente empregado para se reportarem à TV é nhe'engyrú, o que "guarda a fala dentro", como me explicou o velho Kwati. CDs e DVDs, suportes de imagens e sons, também seriam yngyrú, com a diferença que o DVD guarda o ynga enquanto sombra (imagem animada) e voz, e o CD, apenas a voz (ynga). CDs também foram aludidos por outras pessoas como nhe'engyrú.

Até aqui, ynga aparece como princípio e substância vital que anima o corpo e que se manifesta por meio da voz, pulsação e coração, além de "sombra" e "alma". Durante minhas incursões ao campo, interessada nos termos asuriní para as novas imagens e sons (fotografias, filmes, gravações sonoras), obtive outras traduções para o complexo conceito de ynga. As conversas com o jovem xamã Parajuá foram as ocasiões mais elucidativas nesse sentido. Ele afirmou que "[...] o ynga é dois: é sombra e para o pajé é outra coisa". Sombra em relação à imagem que se movimenta na televisão ou à projeção do corpo no chão com a incidência do sol, como ele me mostrava gesticulando numa das situações, e que pode ser considerada como índice da presença do princípio vital animado no corpo. Parajuá continua ao explicar que, para o pajé, ynga também pode se referir a coisas diferentes: “[...] você dorme e sonha, esse aí que vai é ynga, ou então na festa de Tivá, Apykwara e Karovara, de manhã, pega ynga para imunara [posição do paciente nos rituais terapêuticos], pega do espírito e passa para imunara". Nos rituais xamanísticos, o pajé pega o ynga dos espíritos, põe diretamente no paciente, através de gestos e massagens, ou o aplica no mingau e na farinha que serão consumidos pelos imunara. Manipulado nos rituais, "o ynga parece uma teia de aranha branca e só pajé vê [pajé uesak]", disse o jovem xamã.

Parajuá trazia uma importante contribuição ao chamar atenção para o fato de que a perspectiva do xamã em relação ao que seja o ynga difere da dos 
homens comuns. E, para além disso, apontava para uma acepção do termo que eu não conhecia até então, indo além do princípio vital manipulado nos rituais, ao se referir à sua circulação fora do corpo do xamã em momentos de sonho ou viagens ao mundo dos espíritos. Nesses casos, diz Parajuá, “[...] é jeynga [meu ynga], que vai". O ynga aqui, como ele mesmo me apontou, não é uma parte incompleta do xamã, mas é o próprio pajé, uma espécie de imagem corporal animada que se desloca aos mundos dos espíritos e se integra à vida "social" existente nesses mundos, recebendo nomes próprios, casando e tendo filhos.

$\mathrm{O}$ acesso às moradas dos espíritos se dá através de caminhos percorridos apenas pelos xamãs, no momento do sonho ou durante os rituais xamanísticos, na ocasião em que perdem os sentidos e "morrem um pouquinho", como me explicaram alguns Asuriní..$^{22}$ Müller afirma que os xamãs visitariam, também, a aldeia dos avaeté ( avá = gente, eté = de verdade), onde vive Maíra e para onde vão os Asuriní após a morte. Não conto com informações a respeito da "aldeia dos avaeté"; o que ouvi frequentemente é que, quando alguém morre, seu ynga vai para o caminho de Maíra (mairipé), deixando imprecisa a informação se haveria ou não uma aldeia dos mortos nessas proximidades. O interessante aqui é que, como no caso do sonho do xamã, dizem que "a pessoa vai encontrar Maíra", embora seja o seu ynga que viaje, o que nos permite apreender que o ynga é a própria pessoa e não apenas um princípio animado ou a "alma" dissociada do corpo. Outro aspecto importante é que, nos dois casos, ao se referirem ao ynga que aparece dissociado do corpo, o termo vinha precedido de um possuidor; Parajuá me fala em primeira pessoa "jeynga" ou gaynga ( $g a=$ ele) para se referir ao ynga de um pajé no momento de suas viagens cósmicas. No caso da pessoa que morreu, também se referem ao ynga dele ou dela, nesse caso evitando dizer o nome.

Considero que a tradução de ynga por "alma" - nas situações em que este princípio é ejetado do corpo ou mesmo para se referir à sombra da televisão não seja a mais adequada. Pois, nessas situações, "ele é a pessoa", como me indicam os Asuriní, e não a "alma" em oposição ao "corpo". Separado do corpo, o ynga se comporta mais como um duplo, na acepção trabalhada por Vernant (1990) ao

22 Os Asuriní interpretam o "transe extático" como morte. Müller (1993, p. 184) declara nunca ter obtido informações a respeito do momento preciso em que os Asuriní viajam aos mundos dos espíritos nem, tampouco, a respeito das relações entre o transe extático (morte dos xamãs durante os rituais) e as viagens a outras esferas cósmicas. 
falar do substituto do morto na Grécia Antiga, o kolossós, do que como "alma". A ideia de duplo, que será incorporada ao campo dos estudos ameríndios por Carneiro da Cunha (1978), figura uma categoria que pressupõe uma organização mental diferente da nossa.

Assim como a imagem da televisão foi referida pelos Asuriní como sombra, imagem animada e voz (ynga), fotografias podem ser entendidas nessa chave, não como ynga, mas em diálogo com essa complexa noção. Fotografias causaram mortes, pois o ynga, enquanto princípio vital, foi retirado do corpo da pessoa.

Müller (2000, p. 185) já havia notado que os Asuriní se referem à câmera filmadora e fotográfica (e também ao espelho) pelo termo moresakava, traduzido como "o que vê as coisas", pois mor é prefixo de nome coletivo e sujeito indeterminado, uesak é ver, e av(a) é sufixo formador de circunstância. A tradução que Monserrat (1998) propõe para o sufixo av(a) como "nome de lugar ou instrumento" é bastante apropriada para pensar os termos associados às imagens técnicas, já que nessa acepção do sufixo há uma ênfase em nomear instrumentos e objetos. Moresakava, nome dado às câmeras filmadora e fotográfica e também ao espelho, poderia ser, dessa perspectiva, "instrumento ou objeto que vê" ou "aquela máquina ou objeto que vê". Contudo, como me apontaram Parajuá e Muapé, embora o mesmo termo se refira ao espelho, entendido como "objeto para a gente se ver", no caso das câmeras haveria uma inversão na relação entre quem olha e quem é olhado, o que levou a traduzirem moresakava como "aquela máquina que olha a gente", semelhante à oresakava, "a máquina está olhando a gente". A ênfase dos indígenas no movimento e direção do olhar pode ser entendida com dados etnográficos concretos. Em mais de 40 anos de contato, apenas nos últimos dez os Asuriní passaram, ainda que timidamente, a incorporar o uso de equipamentos de produção de imagens; até então, esses instrumentos pertenciam aos brancos e o olhar era sempre unidirecional, de fora para dentro, câmeras olhando para eles.

Filmes podem ser referidos genericamente pelo termo morayngava (mor + ayngava), que Müller traduziu por "imagem das coisas" e que proponho possa ser também "aquele que imita as coisas, torna presente", ou ainda, como sugeriu o indígena Muapé, “o que vai imitar". No caso de ser um filme dos Asuriní, eles diriam janerayngava (jane = nós). Os filmes nos suportes de DVD também podem ser referidos como morayngava, da mesma forma que fotografias (impressas ou digitais) de forma genérica. Fotos dos antigos Asuriní que já morreram (bava) 
são bavarayngava, e, se a pessoa que fala aparecer no retrato, vai dizer jerayngava (je = minha, de mim, eu). Fotografias nas cédulas de identidade são mencionadas como tayngava (fotografia de gente, ser humano, como me explicaram), ou, então, akynguerayngava, para se referir à imagem da cabeça (akynga) separada do corpo (fotos $3 \times 4$ dos documentos), o que é indicado pelo sufixo er, que indica passado (ex-cabeça) ou o estado de separação entre cabeça e corpo. ${ }^{23}$

A respeito das bavarayngava (fotografia dos antigos que já morreram) na ocasião do contato, narrativas afirmam seu caráter patogênico e perigoso. O indígena Takamuin, que tinha por volta de 20 anos quando os missionários católicos se encontraram com eles pela primeira vez, conta que "o padre Antônio tirou fotografia, pegou o ynga e o ynga ficou dentro da máquina”. Apebu também reiterou a informação ao afirmar que "a primeira foto que padre pegou tirou o ynga, aí homem morreu". Em diversos trabalhos abordei extensivamente a ideia da fotografia como objeto patogênico, pela capacidade da câmera fotográfica de sugar o ynga (princípio vital) da pessoa fotografada ao reproduzir sua imagem, ayngava. ${ }^{24}$

Embora atualmente o perigo da fotografia pareça ter praticamente desaparecido, a depender do momento e situação ela pode ter agência deletéria. A circulação do acervo fotográfico de Renato Delarole produzido nas décadas de 1970 e 1980 entre os Asuriní em 2015 foi bastante significativa para obter informações a esse respeito. Como descrevi anteriormente (Villela, 2017), a presença massiva de pessoas falecidas nas fotografias, ao contrário do que poderíamos supor, não causou incômodo algum; diziam sempre que aquelas pessoas "morreram faz tempo" e as memórias a elas associadas poderiam ser lembradas, bem como seu nome, sem prejuízos. Os Asuriní tradicionalmente trocam de nome com a morte de um parente; nesse caso, substituem seus nomes por outros que pertenceram a mortos mais recuados no tempo. ${ }^{25} \mathrm{O}$ tabu em relação ao nome do morto recente continua vivo, e o perigo existe, pois a desintegração da pessoa libera o espectro

23 Er, per ou wer são sufixos de passado nominal, empregados para se referirem aos pedaços do corpo do morto enterrados, indicando que não estão mais integrados à pessoa, por exemplo "ex-cabeça" (akynguera).

24 Ver Villela (2015) para uma discussão da eficácia ou o poder da imagem fotográfica entre os Asuriní pensada em termos da teoria da agência social de Gell (1998), que propõe que se trate "objetos como pessoas". Ver também Villela e Grunvald (2016).

25 Ver Souza (1994), que estudou a nominação entre os Asuriní do Xingu e fez uma etnografia com material de campo de fins dos anos 1980 e início dos 1990. 
anhynga. Nesse caso, pronunciar o nome do morto recente, assim como ver a sua fotografia ou simplesmente se lembrar dele, representa um risco iminente, pois o pensamento, o nome e a imagem podem atrair seu anhynga para perto da aldeia.

Sobre morayngava em referência aos filmes, comentários asuriní também enfatizam sua capacidade agentiva. Aproximações entre o audiovisual e o xamanismo foram sugeridas pelos indígenas pela primeira vez em 1997, na ocasião da exibição do filme A guerra do fogo (1981), que trata do embate de duas tribos de homens primitivos, uma delas de homens-macaco. Durante a sessão, um dos indígenas relacionou o filme que acabara de ver às narrativas xamânicas; segundo Müller (2000, p. 185), ele comentou que o filme faz o mesmo que o xamã quando conta suas viagens cósmicas: faz existir como realidade acontecimentos e lugares só conhecidos por eles. Assim, os relatos do xamã e a imagem em movimento seriam narrativas que fariam existir realidades virtuais, que se encontram no espaço e no tempo mítico. Segundo explicação dada pela antropóloga na ocasião da exibição, os homens-macaco seriam os "antepassados dos brancos", ao que os indígenas concluem que o filme A guerra do fogo fazia existir o passado mítico do homem branco (Müller, 2000, p. 184-185).

\section{Ambiguidade na agência das imagens produzidas pelos brancos}

Ao chamar as imagens fotográficas e audiovisuais de "imagens tecnológicas dos brancos" não queremos apenas chamar atenção para o fato de que se trata de imagens produzidas pela mediação de equipamentos e máquinas provenientes do universo não indígena, mas, sobretudo, que as imagens em contexto asuriní que tratamos aqui foram todas produzidas por brancos, akaraí, no âmbito do contexto indígena, ou que são imagens produzidas fora das aldeias que entram, como os filmes de ficção. De qualquer modo, são trazidas pelos brancos, em última instância, sua agência a eles pertence.

Recuperando a presença da fotografia no contato oficial a partir dessa perspectiva, não se tratou apenas do primeiro contato com o aparato técnico da câmera fotográfica, tratou-se do primeiro contato com os brancos. No primeiro encontro com os padres católicos, a fotografia teria agido de modo patogênico, causando doenças e mortes, mas essa interpretação apareceu a posteriori, 
quando o decréscimo populacional pós-contato fez diminuir progressivamente a população asuriní. No momento do contato com os missionários austríacos, os indígenas são retratados por eles em diversas situações de interação, com poses e sorrisos, conforme explicitei em trabalho anterior (ver Villela, 2018).

Como os Asuriní demonstram em seus relatos, o contato com os brancos foi uma forma de pôr fim às guerras intertribais, consistindo em uma estratégia de sobrevivência. Portanto, mesmo que tenham desconfiado da fotografia desde o primeiro encontro com a câmera dos padres católicos, sua presença foi tolerada como prática inevitável e necessária ao convívio com os brancos. No episódio do primeiro encontro, quem manifestou medo e suspeitou do funcionamento da câmera e das intenções dos padres foi um xamã, mas teria logo sido advertido por outros indígenas para que não protestasse.

A ambiguidade inerente à relação com a fotografia reflete, em certa medida, a ambiguidade segundo a qual se relacionam com os brancos. Embora tenham deixado de ser chamados de tapy'yia, inimigos, passando a ser referidos como akaraí, com quem os Asuriní travam relações amistosas e de parceria, a desconfiança no trato com esses interlocutores está sempre presente. Como disseram alguns indígenas, "os akaraí estão mansos, mas estão ficando bravos de novo". A fotografia e o audiovisual em diferentes suportes funcionam como objetos mediadores da relação com os brancos e, por consequência, o modo como essas novas imagens podem agir causando efeitos está atrelado ao tipo de relação que se estabelece com seus produtores, o que varia, não apenas de acordo com o momento histórico em que estão vivendo os Asuriní, mas também na dependência de quem são os akaraí com os quais dialogam.

As relações com os brancos não são unicamente produtivas e positivas nem apenas conflituosas e suspeitas; elas são tudo isso ao mesmo tempo; relações de amizade e parceria não se dão sem desconfiança e animosidade. Esse mesmo mecanismo é transposto para a relação que os Asuriní estabelecem com as imagens tecnológicas produzidas pelos brancos. A ambivalência da fotografia reside no fato de que pode capturar o ynga da pessoa retratada, tornando-se, assim, um objeto que contém uma fração da pessoa, e que, por isso, se coloca em relação de contiguidade com seu modelo, partilhando o seu princípio vital. No caso da imagem da televisão, do vídeo e do filme, a relação que se estabelece é com o ynga enquanto sombra e voz. A sombra de um corpo no chão é, de certa forma, um efeito projetivo do princípio vital animado; no entanto, 
a sombra separada do corpo também pode remeter aos espectros anhynga, principalmente se a imagem em movimento for de uma pessoa já falecida. Voz e imagens (em movimento e estáticas) separadas do corpo apontam para estados de desintegração ou separação das partes que constituem uma pessoa, o que se vive em ocasiões de adoecimento, morte, ou pelos pajés nas ações rituais e durante os sonhos, momentos em que se deve ter muito cuidado e precaução para que consequências negativas não sejam sentidas.

Relações ambíguas são vividas também com os espíritos. O contato com eles durante os maraká é ameaçador, pois se comportam como animais - devem ser aprisionados, matam, agridem -, mas participam, também, das atividades da aldeia, dançando, fumando e tomando mingau. Dessa maneira, a relação tensa e conflituosa é, também, uma relação de troca: ao espírito se oferece tabaco e mingau, e ele fornece aos humanos o ynga e o moynga.

É ambígua a própria condição dos xamãs. Durante os rituais eles se metamorfoseiam nos espíritos e se tornam um deles, perdem os sentidos ("morrem", dizem os Asuriní) nos maraká terapêuticos associados aos Apykwara, Karovara e Tivá, ou corporificam e os trazem para a terra, comportando-se como um deles durante os rituais propiciatórios ligados à caça e à agricultura, associados aos Tajaho e aos Arapuá. Outra situação que reafirma a condição ambivalente do xamã ocorre durante o sono, quando seu duplo (ynga) viaja aos mundos dos espíritos, locais em que o xamã é socializado: ganha um nome, casa-se, tem filhos.

O que estou chamando aqui de ambiguidade é referido por Müller como a relação de equivalência sem oposição, de isso e aquilo, que é operativa na relação dos Asuriní com os seus outros. A autora diz: “[...] se há a relação com o mundo exterior, fundamento da diferença como condição da sociedade, ela está na concomitância, simultaneidade de estados de alteridade" (Müller, 1993, p. 279, grifo da autora). Parece-me que, a respeito dessa noção filosófica, o xamanismo é um importante modelo; é da condição do xamã de ser, ao mesmo tempo, espírito e humano que deriva a ideia de par, isso e aquilo sem hierarquização. E, dessa maneira, diz Müller (1993, p. 279), "a par dessa função desempenhada pelo xamã, a representação estética também opera neste nível fazendo equivaler representação e realidade [...]".

O que a noção de ayngava nos mostra é que a relação entre um modelo ou um referente e sua imagem vai além de ser somente a de representação do que está ausente, mas, antes, aponta para uma noção de imagem viva em que 
o objeto que imita pode evocar e presentificar o modelo, estabelecendo uma relação de contiguidade com ele, ou simplesmente é parte do referente ou seu duplo. O que Müller (1993, p. 279) chama de "equivalência entre representação e realidade sem hierarquização" pode ser levado mais além, pois a imagem não apenas "equivale ao real", mas o produz; ela "faz existir". Narrativas fílmicas "fazem existir universos virtuais", imagens fotográficas no contato estabeleceram relações potentes e perigosas com corpos das pessoas retratadas.

Como descritas por teóricos da imagem, imagens técnicas como as fotográficas e audiovisuais como formas que apresentam completa identidade com aquilo de que são imagens, ofuscando o trabalho da representação, provocam ambiguidade na percepção e geram confusão. Em contexto asuriní, como procurei mostrar, a ambiguidade também é uma chave para entender a presença dessas imagens que entram de fora nas aldeias indígenas; no entanto, ambiguidade aqui aponta para um sentido bastante diferente. Os Asuriní nos mostram que a agência das imagens produzidas pelas tecnologias dos brancos nada tem a ver com o que Debray (1992) chamou de "arcaísmo pós-moderno". Não se trata aqui de acreditar que a realidade tem seu próprio poder de representação, mas de perceber de maneira bastante sagaz que a agência das imagens produzidas pelos brancos em contexto ameríndio a eles pertencem, e que podem, como outras imagens e objetos no mundo asuriní, provocar efeitos, esconder intencionalidades e serem vetores de agência.

\section{Referências}

BARCELOS NETO, A. Apapaatai: rituais de máscaras no Alto Xingu. São Paulo: Edusp, 2008.

BELTING, H. Pour une anthropologie des images. Tradução de Jean Torrent. Paris: Gallimard, 2004.

BENJAMIN, W. A obra de arte na era de sua reprodutibilidade técnica. In: BENJAMIN, W. Obras escolhidas I: magia e técnica, arte e política. São Paulo: Brasiliense, 1987. p. 165-196.

CARNEIRO DA CUNHA, M. Os mortos e os outros. São Paulo: Hucitec, 1978.

CARNEIRO DA CUNHA, M. Pontos de vista sobre a floresta amazônica: xamanismo e tradução. Mana, Rio de Janeiro, v. 4, n. 1, p. 7-22, 1998. 
CESARINO, P. N. A escrita e os corpos desenhados: transformações do conhecimento xamanístico entre os Marubo. Revista de Antropologia, São Paulo, v. 55, n. 1, p. 75-137, 2012. Disponível em: http://www.revistas.usp.br/ra/article/view/47583. Acesso em: 20 jan. 2019.

DEBRAY, R. Vie e mort de l' image: une histoire du regard en Occident. Paris: Gallimard, 1992. DESCOLA, P. Par-delà nature et culture. Paris: Gallimard, 2005.

GALLOIS, D. O movimento na cosmologia Waiãpi: criação, expansão e transformação do universo. 1988. Tese (Doutorado em Antropologia) - Faculdade de Filosofia, Letras e Ciências Humanas, Universidade de São Paulo, São Paulo, 1988.

GARCIA, U. Karawara a caça e o mundo dos Awá-Guajá. 2010. Tese (Doutorado em Antropologia Social) - Faculdade de Filosofia, Letras e Ciências Humanas, Universidade de São Paulo, São Paulo, 2010.

GARCIA DOS SANTOS, L. Amazônia transcultural: xamanismo e tecnologia na ópera. São Paulo: n-1 edições, 2013.

GELL, A. Art and agency: an anthropological theory. Oxford: Clarendon, 1998.

GONÇALVES, M. A. De Platão ao photoshop: as imagens e suas leituras. Ciência Hoje, Rio de Janeiro, n. 298, p. 12-17, 2010.

A GUERRA do fogo. Direção: Jean-Jacques Annaud. Distribuição: Twentieth Century Fox. Tornhill: International Cinema Corporation, 1981. Filme (100 min), color.

LAGROU, E. A fluidez da forma: arte, alteridade e agência em uma sociedade amazônica (Kaxinawa, Acre). Rio de Janeiro: Topbooks, 2007.

MACDOUGALL, D. Transcultural cinema. Princeton: Princeton University Press, 1998.

MITCHELL, W. J. T. Iconology: image, text, ideology. Chicago: The University of Chicago Press, 1986.

MONSERRAT, R. Língua asuriní do Xingu: observações gramaticais. Altamira: Prelazia do Xingu: Conselho Indigenista Missionário, 1998.

MÜLLER, R. Tayngava, a noção de representação na arte gráfica Asuriní do Xingu. In: VIDAL, L. (org.). Grafismo indigena: estudos de antropologia estética. São Paulo: Edusp, 1992. p. 231-248.

MÜLLER, R. Asuriní do Xingu: história e arte. Campinas: Editora da Unicamp, 1993.

MÜLLER, R. Maraká, ritual xamanístico dos Asuriní do Xingu. In: LANGDON, J. (org.). Xamanismo no Brasil: novas perspectivas. Florianópolis: Editora da UFSC, 1996. p. 153-170. 
MÜLLER, R. Corpo e imagem em movimento: há uma alma nesse corpo. Revista de Antropologia, São Paulo, v. 43, n. 2, p. 165-193, 2000.

SOUZA, M. L. R. Nomes e história do contato entre os Asuriní do Xingu. 1994. Dissertação (Mestrado em Antropologia Social) - Faculdade de Filosofia, Letras e Ciências Humanas, Universidade de São Paulo, São Paulo, 1994.

TAUSSIG, M. Mimesis and alterity: a particular history of the senses. New York: Routledge, 1993.

VERNANT, J. P. Mito e pensamento entre os gregos. Tradução de Haiganuch Sarian. Rio de Janeiro: Paz e Terra, 1990.

VILLELA, A. Quando a imagem é a pessoa ou a fotografia como objeto patogênico. In: CAIUBY NOVAES, S. (org.). Entre arte e ciência: a fotografia na antropologia. São Paulo: Edusp, 2015. p. 109-121.

VILLELA, A. O negativo e o positivo: a fotografia entre os Asuriní do Xingu. 2016. Tese (Doutorado em Antropologia) - Faculdade de Filosofia, Letras e Ciências Humanas, Universidade de São Paulo, São Paulo, 2016.

VILLELA, A. O retorno dos antigos: compartilhamento do acervo fotográfico de Renato Delarole com os Asuriní do Xingu. Revista Mundaú, Maceió, n. 3, p. 70-86, 2017.

VILLELA, A. Fotografia e (des)encontro: a narrativa fotográfica do contato oficial dos Asuriní do Xingu e suas versões. GIS - Gesto, Imagem e Som, São Paulo, v. 3, n. 1, p. 159-176, jul. 2018. Disponível em: http://www.revistas.usp.br/gis/article/ view/142388/141954. Acesso em: 5 jan. 2019.

VILLELA, A.; GRUNVALD, V. Alguns apontamentos sobre fotografia, magia e fetiche. In: BARBOSA, A. et al. (org.). A experiência da imagem na etnografia. São Paulo: Terceiro Nome, 2016. p. 205-228.

VIVEIROS DE CASTRO, E. Araweté: os deuses canibais. Rio de Janeiro: Jorge Zahar: Anpocs, 1986.

VIVEIROS DE CASTRO, E. A inconstância da alma selvagem. São Paulo: Cosac \& Naify, 2002. VIVEIROS DE CASTRO, E. Perspectival anthropology and the method of controlled equivocation. Tipití, v. 2, n. 1, p. 1-20, 2004.

WOLFF, F. Por trás do espetáculo - o poder das imagens. In: NOVAES, A. (org.). Muito além do espetáculo. São Paulo: Editora Senac, 2005. p. 16-45.

Recebido: 31/01/2019 Aceito: 24/06/2019 | Received:1/31/2019 Accepted: 6/24/2019 